\title{
NEXT-GENERATION HABITATION TYPOLOGY: LIVE/WORK/FARM
}

\author{
CAMILO CERRO \\ College of Architecture, Art and Design, American University of Sharjah, UAE
}

\begin{abstract}
In a world where social, financial and ecological systems seem increasingly tenuous, emerging technologies together with a diverse understanding on what constitutes a family unit are starting to reshape our design approach to residential architecture. The idea of the traditional family has given way to multiple types of social micro-communities that are forcing residential design into a much more adaptable typological complexity. Adding to this, it is estimated that by $2020,50 \%$ of the labor force of the developed world will be self-employed, turning their residences into mini-factories where they will produce, package and sell products with the help of the internet and online marketplaces. In this new economy, the idea of the industrial zone, which is a legacy of the twentieth century, will slowly be taken over by live/work residential design. In a similar way, the next generation habitat will reclaim certain elements of farming and resettle them in the city. Technologies like: mushroom production, hydroponic farming, grey water filtration systems, solar and wind energy, composting, and other passive and active advances, will be embedded in a systemic way in a construction process based on the versatility provided by open plan design. To attain this goal, designers will need to understand the systemic interdependence produced at both the macro (urban) and micro (interior) level, generated by the overlap of three concepts: Intelligent housekeeping, emerging technologies and social innovations, as they apply to the life cycle of the household. The result will be a new typology of live/work/farm habitation, designed to educate the user and better their quality of life while generating a socialization of the neighborhoods and a city that looks at the big picture and the interdependence of its components. Keywords: third nature, sustainability, residential design, self-sufficiency, systemic interdependence, standard of living, intelligent housekeeping, emerging technologies, social innovation, live/work/farm.
\end{abstract}

\section{INTRODUCTION}

I will be discussing a new housing typology, designed around the systemic interdependence of three concepts: intelligent housekeeping, emerging technologies and social innovations. The co-relation of which has the potential to create a new type of urban fabric that lives symbiotically in the resulting hybrid between landscape and prefabrication. This new residential typology has been designed to help increase the user's standard of living while creating a conceptual design framework called 'Third Nature' which intends to build on the idea that everything in the world is interconnected and we must see the big picture for change to be possible. Through this conceptual proposal and its resulting architectural design, we will move from the micro to the macro; house to block to city, developing a systemic interdependency between the inhabitants and their surroundings as they participate in the development of a new type of environment for living.

\section{RESIDENTIAL DESIGN}

Half a decade ago American companies moved their headquarters to the suburbs escaping poverty and the social problems of the city. With them, large numbers of workers moved too, following their jobs. Now, with suburbs being the centers of poverty a growing number of companies are moving again, bringing back with them, their working force. The world population is becoming increasingly urban. In 2008, city dwellers formed the majority of the global population, 3.3 billion people, live in urban areas. In the city, the suburban formula 
of houses spaced from each other by a green lawn as a statement of individuality are a logistic nightmare from the perspective of infrastructure. The freestanding house has to give way to the housing unit, swapping introspection for community while adding density to more compact dwellings. As the city provides a smaller footprint for the residential needs of the user, we need to remember that the evolution of ideas that serve as the basis for the development of residential design have always moved in parallel to the needs of the family unit. A residence is a direct mirror of the technological, cultural and social needs of a society that is always changing. And to keep up with these changes, residential design is forced to create new housing typologies to address the changing needs of a population that keeps rewriting the definition of what a family unit is. Today more than ever, the need for versatility together with ideas of self-sufficiency and sustainability are some of the most important factor trying to answer the question of habitation. A question that requires we understand the residence as being part of a system that through its interdependence will define a block and later a city.

\section{TYPOLOGY: LIVE/WORK/FARM}

Typology can be seen as a descriptive device that allowed each generation of architects, urban planners and theorists to restructure the role of urbanity within society, defining the ideology common to all that would function as the set of rules for which architecture at its different scales is developed. Aldo Rossi [1] (1931-1997) in his book "Architecture of the City" defines 'type' as '... the very idea of architecture, that which is closest to its essence.' As residential typologies adapt to population growth and climate change, the descriptive elements that define the idea of residence need to be reassessed. And as a result of this, a new typology has to be proposed, one that describes the evolution or transformation of the subject. To do this, I will start by defining three ideas meant to serve as the conceptual undertone of proposing a new residential typology. The three ideas are: intelligent housekeeping, emerging technologies and social innovations.

Intelligent housekeeping refers to all those systems designed to deal with the day to day life of the residence, including; redefining the handling of garbage, production of in-house food sources, restudying energy and water consumption and cradle to grave material impact. 'intelligent housekeeping' places the house in the context of its neighborhood and ultimately the city. It makes the residence responsible and participant on not only lifting the quality of life of the unit but the community as a whole. Smart homes have the potential to improve home comfort, convenience, security, and energy and water management. It can also be used to help the elderly and people with disabilities, providing a safe and secure environment. At a micro level, it saves money from energy efficiency, the production of food and the reusing of water. While at a macro level it produces less garbage and it is also less dependent on the government for energy, allowing the saved money to be re invested into education and health.

But intelligent housekeeping cannot function alone, it will be dependent on emerging technologies which refers to all the equipment, materials and construction techniques used to build the house. The process starts with the selection of low impact, recycled and reused materials. Then the construction of in-site and prefabricated elements. And finally, the use of advance technologies to control irrigation, insulation, water filtration, solar energy storage, intelligent illumination, etc. But these two concepts (intelligent housekeeping and emerging technologies) can only work under a reassessment of the way we interact with our household. Old habits will have to change to adapt to the new systems, this is where social innovations create a new way of relating to our homes and each other so that we can live in balance with our environment. Ideas like farming, composting, reusing, etc. will be new to some users. These users will be educated by living in the new residential typology and learn to function 
within the system. Another important aspect of social innovation has to do with the freedom provided by having an open plan designed for versatility. The family structure can preorder how they want the bedroom portion of their house compartmentalized; A nuclear family will want a master bedroom and one or two children bedrooms while a childless family might want the space to be reconfigured in some other way. This level of versatility, allows for a level of family specificity without compromising the design of the rest of the unit. And it gives the user the freedom to change the configuration over time without having to make expensive or intrusive renovations to the house. The same adaptability is carried to the ground floor which will be zoned for commercial activity. Designed to be linked to the house, the commercial aspect of the typology will allow different kinds of labor to happen within the residence. The hybrid of these three concepts results in a new residential typology that combines working, living and farming (live/work/farm).

\section{THIRD NATURE}

The idea of 'Third Nature' was coined by Flemming Rafn Thomsen and Ole Schrøder of the architecture and landscape firm Tredje Natur in Copenhagen Denmark [2]. For them Third Nature 'is a holistic perspective, that is based on the idea that the problems of the world cannot be solved by only thinking about the parts of the system and that a framework for a high quality of life is not achieved by solely looking at sustainability, aesthetics, solutions, cities, or nature separately. Nature value is built on the idea that everything in the world is interconnected and we must see the big picture for change to be possible' [3]. Under this premise I first designed a live/work/farm single family residence for the Residential Grand Prix Competition 2016 in Montreal, Canada. That design served to layout the conceptual basis that would evolve to become this project's present reiteration. The project used as a case study for this paper grows from the previous research but it is reassessed in a new form to create middle income housing. For it, the idea of 'First Nature' refers the natural world. Sometimes used in a very romanticized way, it proposes the idea of an environment that is interdependent and to some degree in balance. On the other hand, 'Second nature' could be define as the type of growth that takes place when the urban fabric is allowed to expand out of control, in an invasive unplanned way like in shanty towns. When this happens, it always does so at the cost of the 'First Nature'. And the results are always detrimental to the quality of life of its inhabitants. 'Third nature' then is a symbiotic hybrid that creates a system of interconnected elements. It is the capacity of design to help architecture develop a hybrid that is able to produce a new type of environment, mixing urban and natural components in a symbiotic way to educate, feed, empower and better the quality of life of the population. This hybrid needs to work at a micro and macro scale. It needs to function at the residential level but also at the urban one.

\section{METHODOLOGY}

The live/work/farm proposal was designed as an attempt to provide a basis to address all the issues covered previously at a residential and an urban scale. To do this the following methodology was developed:

- An analysis of different literature sources was established to define trends and features of sustainable residential design.

- An analysis of previous projects produced in house and by others that followed the same conceptual approach were stablished.

- By defining a site questions of: Site specificity, environmental material impact and prefabrication alternatives were studied and assessed. 
- A design was created and taken to 'design development' stage so it could be reviewed by peer designers.

- $\quad 3 D$ Models were produced to analyze sun path, insulation requirements and energy consumption.

\section{CASE STUDY: FROM MICRO TO MACRO}

Humans have a tendency to look for things that we like while avoiding those that we dislike. Food is one of those things that we like and because of this the kitchen has become the center of residential life. In the proposed project, the kitchen is at the crossroads of an open plan and an external terrace on the first floor of the building. It is a crossroads not only because of physical location but more importantly because it is the point at which the 'live' and 'farm' components of this new residential typology meet.

The kitchen (Figs 1 and 4) is the center of an interdependent, systemic cycle that allows the residence to produce its own food. In winter, the kitchen has two different types of hydroponic technologies growing produce: A kinetic hydroponic vertical garden following the stair shaft and a hydroponic growth system embedded in the main built in fixture over the kitchen based on the Nano model by Hyundai. When the cold weather ends, this production gets increased by external gardens at both ends of the residential building and a third garden at the terrace across from the kitchen. The production of food has the potential to help in the homes finances by reducing the dependency to external produce. Urban gardening is a way for diversifying our sources of food. In one study, it was estimated that the average vegetable gardener in Newark, NJ could expect to net $\$ 475$ worth of produce, with only a $\$ 25$ investment in their garden [4]. The kitchen is also linked to an internal water filtering system that connects all water use in the residence, separating grey water to be filtered and reused for all 'live', 'work' and 'farm' environments. Organic and inorganic garbage get normally

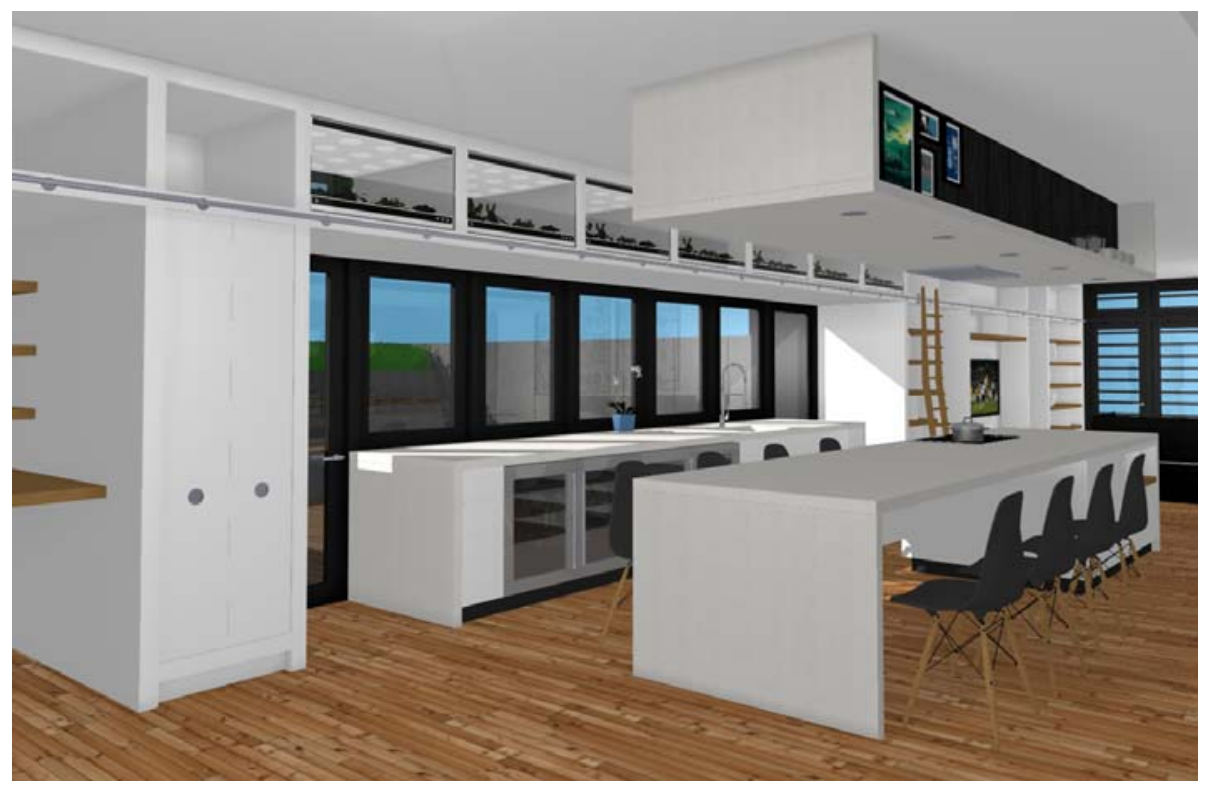

Figure 1: Open kitchen with hydroponic farm units above window line. 
recycled at the kitchen. The organic elements get feed to a worm tower that produces compost for the external gardens, minimizing the house holds production of trash. The kitchen as the center of an open plan divides internal and external spaces. The open plan (Figs 2 and 4) uses one of its longitudinal walls for the placement of a continuous built in furniture wall designed to house; kitchen, toilet, home office and meditation room. This fixture allows for the rest of the space on the first floor to remain open facilitating cross ventilation across the space.

The second floor provides a rectangular plan that can be separated into different room configurations depending on the users. The idea behind this special adaptability is not only to provide options to the different family types but also, to provide the capacity to change configurations as the family changes through time. Rooms can be rearranged by just moving, adding or removing partitions. A façade of windows brings light into all the rooms, were the windows pop out from the wall line to control the incidence angle of light. The second floor is separated from one of the walls so that skylights above the circulation space provide natural light to the residence during the day. The residential unit rests on top of the 'work' space and they are connected by a stair. The stair has a skylight designed to bring light to a hanging wall of hydroponic plants that spans three levels inside the shaft produced by the stair. The hydroponic vertical farm rotates bringing the plants towards the skylight several times a day. The household has solar panels on the roof, designed to blend visually with the external metal cladding of the building. The panels are connected to a tesla battery that collects the energy for future use. The residences capacity for energy self-sufficiency is directly dependent on its location.

Finally, as we move down to the ground floor, we find a multipurpose space designed to solve the 'work' aspect of this proposed new residential typology. According to the Bureau of Labor Statistics, as of May 2015, 15.5 million people in the US were self-employed [5] and it is estimated that by $2020,50 \%$ of the labor force of the developed world will be selfemployed (Intuit report, 2010 [6]). This means the residence of the future will have to provide adequate space to allow for multiple types of small scale factories, professional offices and

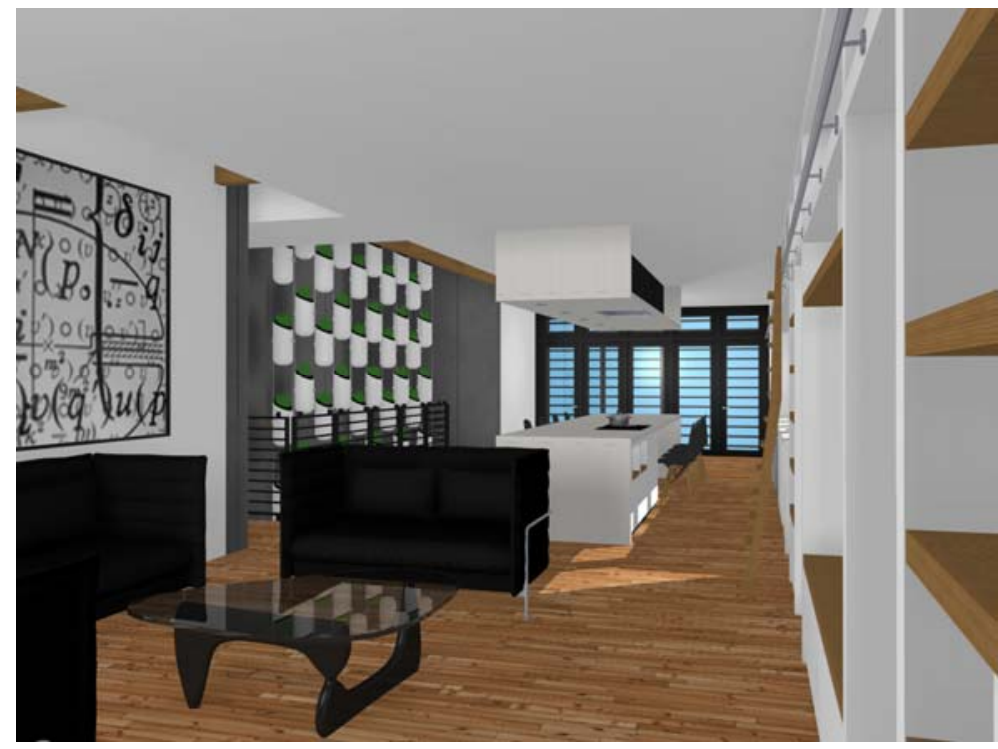

Figure 2: Open plan at first floor, showing hydroponic vertical farm. 


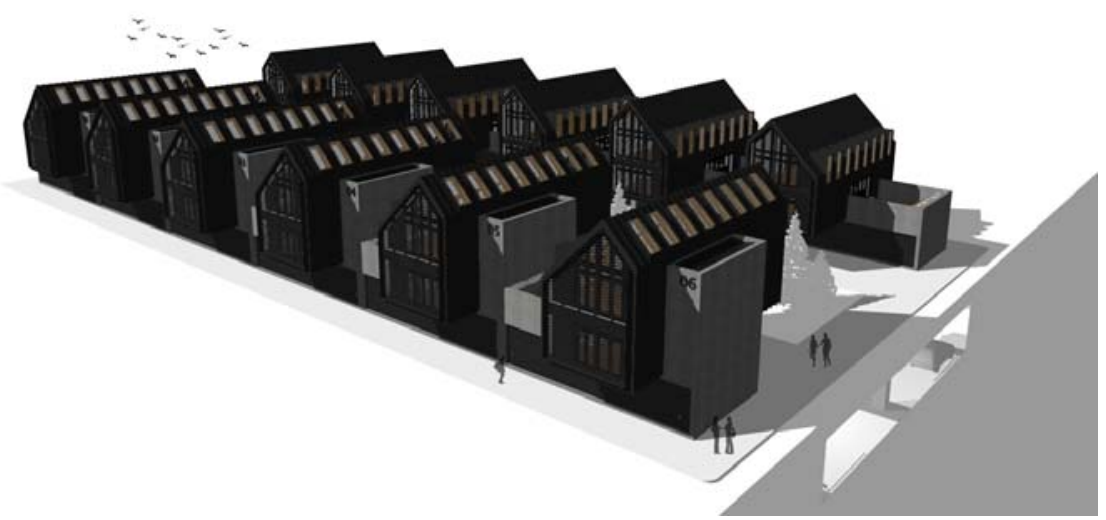

Figure 3: Housing block with central semi-private space and underground parking.

other types of small businesses to develop. The open space in the ground floor will serve as the entry to the residence, but it will also provide space for where the users can develop their business. The space has two facades; one faces the street while the other faces an internal park that cuts through the proposed block. In this way, the building provides two façade options to the user. The park running in the middle of the two lines of buildings covers a parking structure (Fig. 3) designed to also serve as a water catching system for flood prevention. Over all we end up with a new typology (live/work/farm) that is designed to increase the quality of life of the user and his/her community.

\section{CONCLUSION}

The aim of this project was to develop a feasible new typology of residential design that answered specific questions about the way family units are evolving, with the aim to address their needs and better their quality of life by providing:

- Versatility in the design process to accommodate, not only the different types of family units that exist but also how they will change through time.

- An indoor farm system capable of providing the user with food all year around, intended to provide better nutrition and produce financial savings to the household.

- Energy independence through the use of solar power.

- The capacity to filter and reuse grey water through the residence.

- A commercial space that adapts to the future requirements of the developing world tendency to work from home.

- A semiprivate green space designed to deal with water surplus due to climate change that creates a space for the development of community and which also helps provide the city with a natural air filter.

- An underground parking lot to minimize the space wasted to car parking which will also serve as a flood prevention tool.

- The decrease in waste product due to composting technologies.

- A residential typology that will help educate by use in the subject of sustainability.

This residential proposal provides a conceptual framework that allows to move from the residential to the urban scale, developing a systemic interdependency between the inhabitants and their surroundings as they participate in the development of a new type of environment for living. 


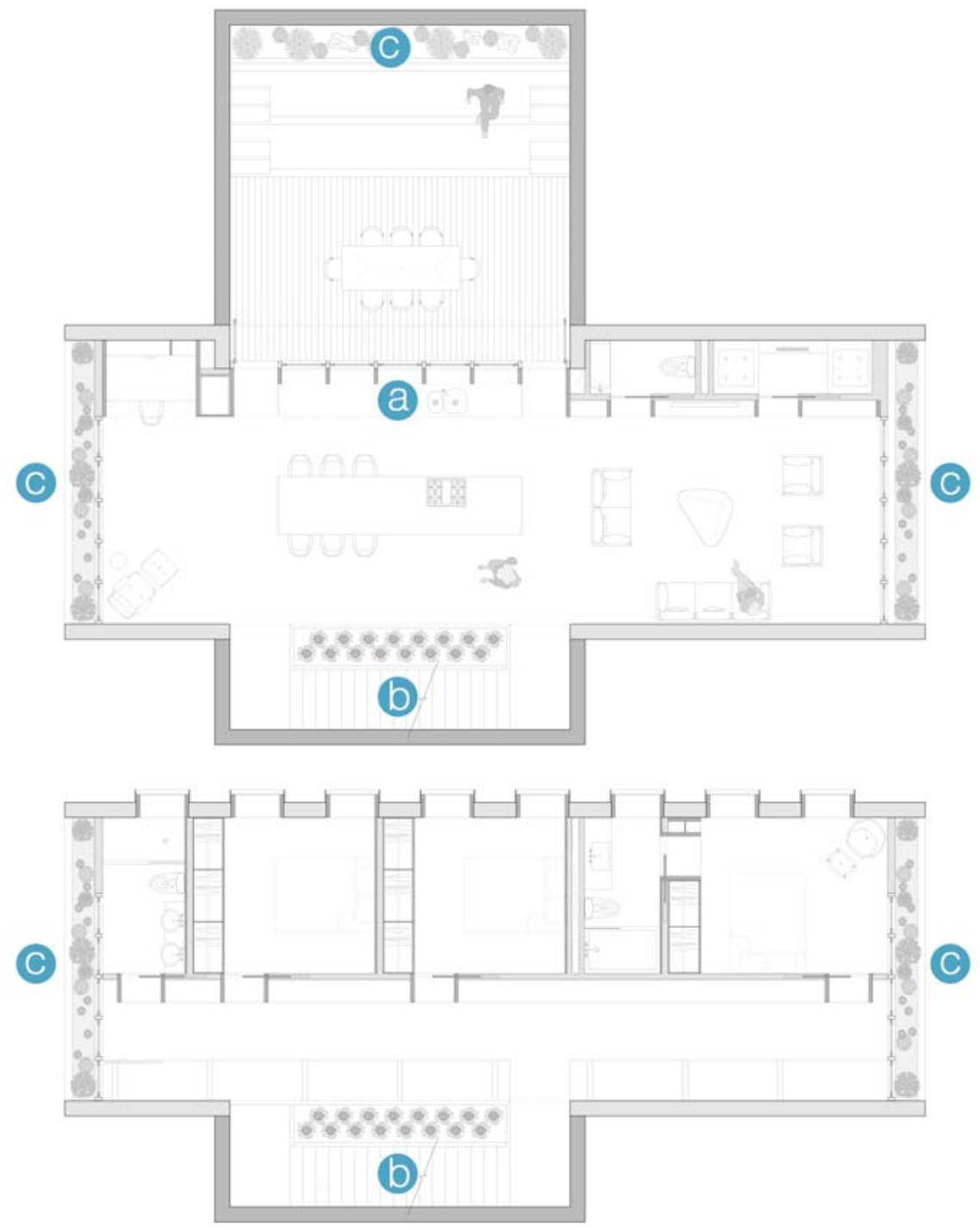

Figure 4: First-floor plan showing open-plan layout and second-floor plan showing one of the possible configurations of rooms. In addition, the three types of farms: (a) The hydroponic system above the kitchen's window line; (b) The vertical hydroponic farm; (c) The external gardens.

\section{ACKNOWLEDGEMENT}

The design proposed for the kitchen is an evolution of a previous idea that won the Open Group-Mia Cucina Design \& Research Award in an international competition named 'Reinventing Home Kitchen Design Competition', that took place in Hong Kong in 2016. 


\section{REFERENCES}

[1] Rossi, A., The Architecture of the City, trans. D. Ghirardo \& J. Ockman, MIT Press: Cambridge, p. 41, 1982.

[2] Rafn Thomsen, F., Third Nature. Towards Empathetic, Transparent and Engaging Cities, UTZON (x) Lecture series, 13:00, 8 Oct., Create campus, fall 2014.

[3] Raakjær, A.S., Schrøder, O. \& Rafn Thomsen F., Nature Value, tredje natur, http://tredjenatur.dk/en/nature-value/. Accessed on: 13 Jan. 2017.

[4] Patel, I. Gardening socioeconomic impacts. Journal of Extension, 29(4), Article 4FEA1, 1991.

[5] United States Department of Labor, Bureau of Labor Statistics, https://www.bls.gov/news.release/empsit.t09.htm. Accessed on: 13 Jan. 2017.

[6] Emergent Research in partnership with Intuit Inc., Intuit 2020 Report, 2010, http://about.intuit.com/futureofsmallbusiness/. Accessed on: 13 Jan. 2017. 